\title{
APLIKASI PENGENALAN SENI KERAJINAN TANGAN \\ MASYARAKAT DAYAK PROVINSI \\ KALIMANTAN TENGAH \\ BERBASIS ANDROID
}

\author{
Ferdiyani Haris $^{1}$, Tri Kurnia Ningsih ${ }^{2}$ \\ Sistem Informasi, Sekolah Tinggi Manajemen Informatika dan Komputer \\ (STMIK) Palangka Raya \\ Jl. G.Obos No.114, Palangka Raya 73112 Kalimantan Tengah, Indonesia \\ Email : sabila006@gmail.com¹,c125520101013@gmail.com²
}

\begin{abstract}
Smartphone has an important role in the world of information. This is because some smartphone already have more functions and capabilities beyond basic capabilities. The most popular smartphone today is A smartphone with Android-based information systems. Utilization of smartphone as A companion in carrying out daily activities is very often used is fundamental in the making recognitions Application Of Handicrafts Dayak's People in Central Borneo Province Based on Android.

The problem of this research is how to design and create recognitions Application Of Handicrafts Dayak's People in Central Borneo Province Based on Android that can help users to provide ease in the knowledge of handicrafts from Central borneo. So it can be know later by the public, not only the locals people but people outside the region.

The method used in this research include observation, interviews, literature and documentation. Software development method that used for creation flow system using methods developed software system development life cycle ( SDLC) with the waterfall model development approach. Software used in the manufacture of recognitions Application Of Handicrafts Dayak's People in Central Borneo Province is A version of the Eclipse ADT Mars.2.
\end{abstract}

Keywords : Android, Application, Art, Dayak's People, Handycrafts.

\section{PENDAHULUAN}

Bangsa Indonesia merupakan bangsa yang kaya akan keanekaragaman hasil budaya. Keanekaragaman hasil kebudayaan itu bisa dilihat dari wujud nilai-nilai, norma-norma, tindakan dalam hidup bermasyarakat dan bersosialisasi.

Seiring perkembangan zaman, kepedulian pelestarian keanekaragaman
Tradisional khususnya kerajinan tangan menjadi sangat sedikit. Hasil-hasil kerajinan tangan nenek moyang yang ada pada masyarakat Indonesia saat ini sudah jarang diajarkan kepada penerusnya, dikarenakan pengaruhpengaruh kemajuan teknologi saat ini. Dengan memanfaatkan teknologi yang ada, penulis merasa penting untuk 
menghubungkan Aplikasi seni kerajinan tangan masyarakat Dayak Provinsi Kalimantan Tengah dengan teknologi yang baru saat ini yaitu teknologi Smartphone berbasis Android.

Smartphone mempunyai peranan penting dalam dunia informasi.Hal ini dikarenakan beberapa smartphone sudah memiliki fungsi dan kemampuan lebih dari sekedar fungsi dasarnya. Smartphone yang paling populer saat ini adalah smartphone dengan sistem informasi berbasis android.

Android merupakan sistem operasi yang bersifat open source, sehingga memberikan kesempatan kepada pengembang untuk melakukan pengembangan sesuai dengan yang diharapkan. Pengguna (user) hanya perlu menginstal aplikasi yang akan digunakan pada smartphone, setelah aplikasi sudah terinstal aplikasi langsung dapat digunakan pada perangkat smartphone. Pemanfaatan perangkat smartphone sebagai pendamping dalam melaksanakan kegiatan sehari-hari sudah sangat sering digunakan merupakan dasar dalam pembuatan aplikasi Pengenalan Seni Kerajinan Tangan Masyarakat Dayak Provinsi Kalimantan Tengah Berbasis Android. Diharapkan dengan adanya aplikasi ini nantinya tidak hanya dari masyarakat lokal tetapi juga masyarakat luar dapat lebih mengetahui dan mengenal hasil kerajinan tangan dan diharapkan dapat turut serta menjaga, memelihara serta melestarikan seni kerajinan tangan yang ada di Kalimantan Tengah.

Dalam Aplikasi Pengenalan Seni Kerajinan Tangan penulis mengambil 4 (empat) Kabupaten yang terletak di Provinsi Kalimantan Tengah yaitu Kabupaten Pulang Pisau, Kabupaten Kapuas, Kabupaten Kotawaringin Timur dan Kabupaten Kotawaringin Barat. Dimana dari 4 (empat) Kabupaten tersebut penulis merasa perlu untuk memperkenalkan hasil seni kerajinan tangan dan mempromosikannya baik kepada masyarakat lokal maupun masyarakat luar daerah.

\section{KAJIAN TEORI}

\section{Aplikasi}

Menurut Aditya (2011:9) aplikasi adalah proses dimana keperluan pengguna diubah kedalam bentuk paket perangkat lunak.

Dari definisi di atas, dapat disimpulkan bahwa aplikasi adalah suatu proses pengerjaan tugas-tugas dari cara manual yang ditransformasikan ke komputer ataupun perangkat lain seperti 
smartphonedengan membuat sistem atau program agar data diolah berdaya-guna secara optimal didalam melayani kebutuhan akan semua aktivitas atau proses yang hampir dilakukan manusia.

\section{Android}

Menurut Nugroho (2013:2) android adalah sebuah sistem operasi mobile yang berbasiskan pada versi modifikasi dari Linux Pertama kali sistem operasi ini dikembangkan oleh perusahaan Android.Inc. nama perusahaan inilah yang pada akhirnya digunakan sebagai nama proyek sistem operasi mobile tersebut, yaitu sistem operasi Android.

Android adalah sistem operasi yang sangat populer di masyarakat. Hampir semua gadget canggih memiliki sistem berbasis android. Mulai dari jam tangan, handphone, tablet PC, televisi, kamera dan alat canggih lainnya menggunakan android sebagai sistem operasinya. Bahkan android akan diimplementasikan kedalam komputer (Irsyad, 2015:1-2).

Kelebihan android dibanding dengan pesaing-pesaingnya antara lain:

a. User Friendly: dalam artian Android sangat-sangat mudah dioperasikan dan dapat dipelajari dengan waktu yang singkat.

b. Bersifat Open Source: Yaitu dapat mengoperasikan atau mengembangkan android tanpa harus membayar.

c. Masyarakat: sistem operasi ini sangat cocok untuk berbagai kalangan. Dari kelas bawah sampai kelas atas sangat banyak yang menggunakan android.

d. Dukungan berbagai aplikasi: Android didukung oleh ribuan bahkan jutaan aplikasi yang tersedia untuk menunjang kinerjanya android.

e. Bersifat Open Source, merakyat, dukungan berbagai aplikasi.

Secara umum android adalah sistem operasi yang digunakan dismartphone dan juga tablet $P C$. Fungsinya sama seperti sistem operasi Symbian di Nokia, iOS di Apple dan BlackBerry OS.

Komponen android, yaitu android SDK (Software Development Kit)merupakan sebuah tools yang siperlukan untuk mengembangkan aplikasi berbasis Android menggunakan bahasa pemograman Java. Pada saat ini android SDK (Software Development Kit) telah menjadi alat bantu dan API 
(Aplication Programming Interface) untuk mengembangkan aplikasi berbasis android. Android SDK bersifat gratis dan bebas dikembangkan karena androidbersifat open source. Berikut adalah garis besar pada arsitektur yang android miliki:
a. Applications dan widget.
b. Applications Frameworks.
c. Libraries.
d. Android Run Time.
e. Linux Kernel

Adapun komponen-komponen android:

a. Activity menyajikan antar muka visual yang digunakan sebagai interaksi pengguna.

b. Intent merupakan object yang memegang isi pesan.

c. Activity menyajikan antar muka. Activity berinteraksi dengan pengguna dalam jangka waktu yang lama dan tetap aktif.

Adapun File Manifest android:

a. Sebelum android dapat memulai component aplikasi, maka android harus melihat component yang sedang berjalan.

b. Untuk itu, aplikasi akan mendeklarasikan component yang mereka gunakan dalam sebuah file manifest yang digabungkan ke dalam paket file android berekstensi (.apk).

c. File manifest ini berstruktur XML dan selalu diberi nama AndroidManifest.xml untuk semua aplikasi.

Spesifikasi minimum pemakaian Aplikasi Seni Kerajinan Tangan Masyarakat Dayak Provinsi Kalimantan Tengah:

\section{a. Android \\ Handphone dengan minimum OS} android versi 4.1 (Jelly Bean) untuk dapat menjalankan aplikasidanRAM $512 \mathrm{MB}$

Android versi4.1(Jelly Bean) membawa sejumlah keunggulan dan fitur baru dengan peningkatkan input keyboard, desain baru fitur pencarian, UI (user interface) yang baru dan pencarian melalui voicesearch yang lebih cepat. Versi ini juga dilengkapi Google Now yang dapat memberikan informasi yang tepat pada waktu yang tepat. Salah satu kemampuannya adalah penggunaan voice search yang lebih cepat dan dapat mengetahui informasi cuaca.
b. Blackberry
Blackberry dengan OS versi 10.2.1 seperti tipe handphone Blackberry Z10, Blackberry Z3, 
Blackberry Q5 dan tipe Blackberry Q10.

\section{Perangkat Lunak Yang Digunakan}

\section{Eclipse}

Menurut Nugroho (2013:2) Eclipse yaitu sebuah IDE (Integrated Development Environment) untuk mengembangkan perangkat lunak dan dapat dijalankan di semua flatform (platform-independent).Berikut ini adalah sifat dari Eclipse:

a. Multi-platform: Target sistem operasi Eclipse adalah Microsoft Windows, Linux, Solaris, AIX, HP$U X$ dan Mac OS X.

b. Mulit-language:Eclipse dikembangkan dengan bahasa pemrograman Java, akan tetapi Eclipse mendukung pengembangan aplikasi berbasis bahasa pemrograman lainnya, seperti C/C++, Cobol, Python, Perl, PHP, dan lain sebagainya.

c. Multi-role: Selain sebagai IDE untuk pengembangan aplikasi, Eclipse pun bisa digunakan untuk aktivitas dalam siklus pengembangan perangkat lunak, seperti dokumentasi, test perangkat lunak, pengembangan web, dan lain sebagainya.

\section{Adobe PhotoshopCS6}

Menurut Sugianto (2011:2) Adobe photoshop merupakan aplikasi pengolah foto yang sangat populer dan andal. Photoshop banyak digunakan oleh kalangan profesional ataupun pengguna awam yang menyukai desain grafis karena memiliki fasilitas yang lengkap dan tampilan yang mudah digunakan untuk memberikan hasil desain yang optimal. Adobe photoshop selain tangguh dalam mengedit dan memanipulasi, juga menyediakan fasilitas-fasilitas lain yang menarik untuk memenuhi setiap kebutuhan, seperti pengaturan warna yang semakin akurat, penggunaan fasilitas efek dan filter yang semakin canggih dan fasilitas pemodifikasian teks yang semakin unik dan fantastik.

\section{ANALISIS DAN DESAIN SISTEM}

1. Analisis

Dalam tahapan analisis ini dijelaskan beberapa faktor yang diperlukan oleh sistem termasuk perangkat keras yang akan digunakan sampai diperlukannya perancangan perangkat lunak, sehingga perangkat lunak tersebut sesuai dengan maksud dan tujuan dibangunnya sistem tersebut. 
Berikut adalah tahapan-tahapan analisis sistem yang dilakukan oleh penulis:

2. Analisis Sistem yang Berjalan

Analisis sistem merupakan tahapan yang sangat penting karena apabila terjadi kesalahan ditahap ini akan menyebabkan kesalahan yang lain ditahap selanjutnya. Analisis sistem dapat didefinisikan sebagai penguraian dari suatu sistem informasi yang utuh kedalam bagian-bagian komponennya dengan maksud untuk mengidentifikasikan, mengevaluasi pemasalahan-permasalahan, kesempatan dan hambatan yang terjadi, serta kebutuhan yang diharapkan dapat diusulkan perbaikan-perbaikan yang akan dilakukan. Analisis sistem meliputi survei dan analisis terhadap sistem informasi yang sedang berjalan. Tahap ini akan menentukan infromasi yang diperlukan oleh para pengguna dari sistem yang baru dan persyaratan teknik dari sistem itu sendiri.

Tahap analisis masalah akan dibahas tentang analisis kelemahan sistem dan analisis kebutuhan sistem seperti kebutuhan perangkat keras (hardware), kebutuhan perangkat lunak (software), kebutuhan informasi dan kebutuhan pengguna.
3. Analisis Kebutuhan sistem

a. Kebutuhan Informasi

Output (pengeluaran) pada aplikasi ini berupa informasi pengenalan hasil seni kerajinan tangan masyarakat dayak Provinsi Kalimantan Tengah, dimana berupa gambar hasil kerajinan tangan dari setiap Provinsi yang diangkat, informasi mengenai pengertian kerajinan tangan, serta menampilkan sekilas informasi umum sejarah singkat Kalimantan Tengah. Adapun sasaran output yang dicapai dalam penelitian ini adalah sebagai berikut:

1) Mengefektifkan dan mengefisiensikan dalam rangka kegiatan promosi dan memperkenalkan hasil seni kerajinan tangan masyarakat Dayak khususnya dari Kabupaten yang penulis angkat agar dapat dikenal tidak hanya masyarakat lokal tetapi dapat dikenal oleh masyarakat dari luar daerah.

2) Meningkatkan kepedulian dan minat masyarakat khususnya masyarakat daerah itu sendiri terhadap seni kerajinan tangan agar lebih menghargai hasil 
karya seni, serta menumbuhkan minat masyarakat untuk turut melestarikan seni kerajinan tangan budaya daerah.

b. Kebutuhan Perangkat Keras (Hardware) Dalam Pembuatan Aplikasi

Dalam penelitian ini spesifikasi perangkat keras yang digunakan adalah sebagai berikut:

1) Processor Intel ${ }^{(\mathrm{R})} \mathrm{Celecon}^{(\mathrm{R})} \mathrm{CPU}$ N2840@2.16GHz 2.16 GHz

2) Memory 2 Gb RAM

3) Hard disk $500 \mathrm{~Gb}$

4) Monitor LCD 11"

c. Perangkat Keras untuk Implementasi Aplikasi yang dibuat

1) Asus_Z00ED

2) RAM $2 \mathrm{~Gb}$

3) Sistem Operasi Android 5.0 (Lollipop)

4) Memori Internal $16 \mathrm{~Gb}$

5) Spesifikasi minimum untuk menjalankan program aplikasi ini adalah mobile phone dengan sistem operasi berbasis android 4.1 Jellybean

d. Kebutuhan Perangkat Lunak (Software)

Kebutuhan perangkat lunak ini terbagi menjadi 2 bagian. Bagian- bagian tersebut adalah sebagai berikut:

1) Personal Computer (PC)

Adapun perangkat lunak yang dibutuhkan pda PC adalah sebagai berikut:

a) Sistem Operasi: Windows 8, System Type 64-bit Operating System.

b) Eclipse win64

c) Plugin ADT 22.2.2

d) Android SDK

e) Java Development Kit (jdk8u5-windows-x64)

f) Sqlitestudio 2.1.5

2) Handphone (Mobile Device)

Adapun perangkat lunak yang dibutuhkan pada Handphone adalah sebagai berikut:

a) Android Operating System Versi 5.0.2 (Lollipop)

b) Java MIDP Emulator

e. Kebutuhan Pengguna

Pengguna (user) Aplikasi Pengenalan Seni Kerajinan Tangan Masyarakat Dayak Provinsi Kalimantan Tengah yaitu umum yang membutuhkan informasi mengenai hasil kerajinan tangan masyarakat dayak. Agar pengguna dapat menjalankan Aplikasi, maka 
pengguna harus menggunakan/ mengoperasikan smartphone berbasis Android, serta OS minimal 4.1.0 (JellyBean).

f. Kebutuhan Fungsional

Kebutuhan fungsional adalah pernyataan layanan sistem yang harus disediakan, serta bagaimana sistem bereaksi pada input tertentu dan bagaimana perilaku sistem pada situasi tertentu. Sedangkan kebutuhan fungsional user merupakan pernyataan level tinggi dari apa yang seharusnya dilakukan sistem, tetapi kebutuhan fungsional sistem menggambarkan layanan sistem secara detail. Beberapa kebutuhan fungsional dari sistem ini adalah:

1) Sistem mampu menampilkan Splash Screen.

2) Sistem mampu menampilkan menu utama Pengenalan Seni Kerajinan Tangan Masyarakat Dayak Provinsi Kalimantan Tengah.

3) Sistem ini mampu menampilkan informasi sejarah singkat Kalimantan Tengah.

4) Sistem ini mampu menampilkan informasi hasil kerajinan tangan Masyarakat Dayak Provinsi
Kalimantan Tengah dari 4 Kabupaten yang penulis angkat dan miimal 3 kerajinan yang akan ditampilkan.

5) Sistem ini memampilkan menu bantuan untuk petunjuk menjalankan aplikasi.

6) Sistem ini menampilkan menu tentang, dimana menjelaskan isi tentang aplikasi dan menjelaskan profil pembuat aplikasi.

7) Sistem ini menampilkan menu keluar, dimana berfungsi untuk keluar dari aplikasi.

g. Kebutuhan Non-Fungsional

Kebutuhan non-fungsional merupakan batasan layanan atau fungsi yang ditawarkan sistem, untuk dapat menjalankan dan mendapatkan informasi dan fungsi dari sistem Aplikasi Pengenalan Seni Kerajinan Tangan Masyarakat Dayak Provinsi Kalimantan Tengah ini, maka pengguna (user) memerlukan sebuah device mobile sebagai media untuk implementasi. Sehingga pengguna harus memiliki smarphone berbasis android agar dapat menjalankan aplikasi tersebut dan minimal OS (Operating System) yang 
digunakan adalah versi 4.1.0 (JellyBean).

4. Analisis Kelayakan Sistem

Agar sistem baru yang dibangun dapat dinyatakan layak untuk dipublikasikan dan dapat digunakan, maka diperlukan beberapa analisis kelayakan sistem. Adapun analisis kelayakan sistem yang dilakukan adalah sebagai berikut:

a. Kelayakan Teknologi

Kelayakan teknologi yang diberikan oleh software aplikasi Pengenalan Seni Kerajinan Tangan Masyarakat Dayak Provinsi Kalimantan Tengah Berbasis Android bagi pengguna ialah perangkat lunak ini dapat memberikan kemudahan untuk mendapat informasi menganai hasil seni kerajinan tangan dari empat Kabupaten yang penulis angkat.

b. Kelayakan Hukum

Ditinjau dari hukum, sistem yang dihasilkan merupakan karya asli penulis dan tidak menyalahi lisensi penggunaan perangkat lunak dalam pembuatan software. Karena perangkat lunak yang digunakan merupakan softwareopen source. Semua isi materi hasil seni kerajinan tangan dikaji dari sumber dan referensi, sehingga secara hukum aplikasi ini dinyatakan layak.

c. Kelayakan Operasional

Untuk kelayakan operasional aplikasi ini nantinya akan digunakan oleh pengguna sebagai media informasi mengenai hasil seni kerajinan tangan masyarakat dayak Provinsi Kalimantan Tengah dengan cara memasang format apk. Pada Smartphone. Pengoperasian aplikasi ini sangat mudah sama halnya menggunakan aplikasi-aplikasi lainnya.

d. Kelayakan Ekonomi

Kelayakan ekonomi pada aplikasi ini sangat jelas jika ditinjau dari penerapannya. Aplikasi ini nantinya akan diterapkan pada handphone yang menggunakan teknologi/ operating system android, karena bagi pengguna handphone berbasis android dapat menggunakan aplikasi pengenalan seni kerajinan tangan masyarakat dayak Provinsi Kalimantan Tengah dengan gratis. Mengingat sudah banyak pengguna (user) yang menggunakan handphone berbasisandroiddan rata-rata sudah mengimplementasikan teknologi tersebut. 


\section{Desain Sistem}

Pada tahapan ini menguraikan secara rinci dari berbagai bentuk desaindesain yang menjadi komponen penyusunan Aplikasi Pengenalan Seni Kerajinan Tangan Masyarakat Dayak Provinsi Kalimantan Tengah Berbasis Android, dimana akan dijelaskan sebagai berikut:

1. Desain Proses

Desain proses merupakan tahapan yang menguraikan konsep pemodelan proses sistem yang dibuat dengan pemodelan fisik (phisical model) dengan menyesuaikan paradigma pengembangan perangkat lunak yang diperlukan. Dalam pembuatan Aplikasi Pengenalan Seni Kerajinan Tangan Masyarakat Dayak Provinsi Kalimantan Tengah penulis mendesain aplikasi ini menggunakan diagram UML (Unified Modelling Language). UML yang digunakan untuk memodelkan desain sistem pada aplikasi ini menggunakan beberapa diagram, antara lain use case diagram, classd iagram, sequence diagram dan activitydiagram.

a. Use Case Diagram

Diagramuse case bertujuan untuk mengambarkan sebuah fungsi dari sistem. Pada Gambar 1, digambarkan tentang cara menggunakan aplikasi yang diawali dengan cara menjalankan aplikasi tersebut, kemudian pengguna melihat daftar menu pada menu utama terlebih dahulu dan memilih salah satu dari daftar yang ada, selanjutnya sistem akan menampilkan informasi serta materi sesuai pilihan pengguna. Sebuah diagram use case mengidentifikasi aktor yang terlibat dalam kegiatan yang dapat dilakukan terhadap aplikasi. Dalam hal ini meliputi user (pengguna) dan sistem.

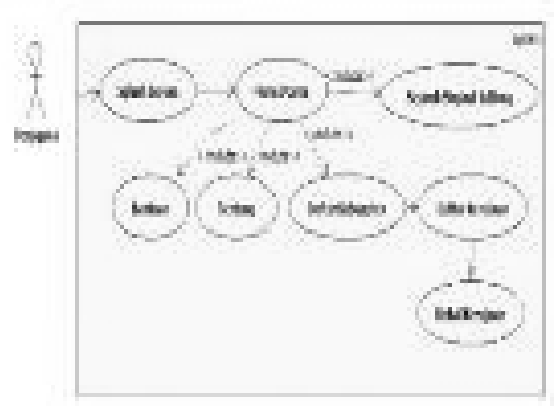

Gambar 1.Use Case Diagram

b. Class Diagram

Class diagram adalah suatu diagram yang memperlihatkan atau menampilkan struktur dari sebuah sistem, sistem tersebut akan menampilkan sistem kelas, atribut dan hubungan antara kelas pada suatu sistem setelah selesai 
membuat diagram. Pada Gambar 2, Class Diagram Aplikasi Pengenalan Seni Kerajinan Tangan Masyarakat Dayak Provinsi Kalimantan Tengah menggambarkan class-class yang ada dalam suatu sistem aplikasi yang nanti akan dikembangkan, dimana classclas tersebut saling berelasi antara yang satu dengan yang lainnya.

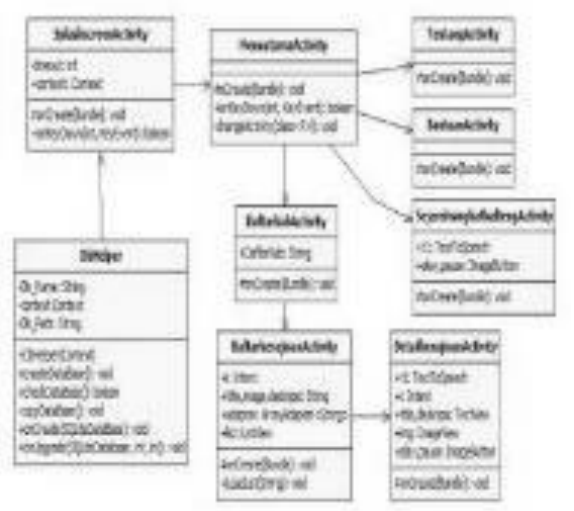

Gambar 2.Class Diagram

\section{c. Sequence Diagram}

Sequence diagram merupakan diagram yang digunakan untuk menggambarkan interaksi antar objek dengan penekanan pada urutan proses atau kejadian baik di dalam atau di sekitar sistem. Untuk memperlihatkan masing-masing aksi yang terdapat pada sistem ini, maka penulis menggunakan sequence diagram.

Adapun sequence untuk masingmasing aksi adalah sebagai berikut:
1) Sequence Diagram Menu Utama

Sequence menu utama memperlihatkan urutan aksi yang terjadi ketika pengguna (user) memulai aktivitas lihat informasi pada menu utama. Pengguna dapat memilih menu yang tersedia pada menu utama, dimana nantinya sistem akan menampilkan informasi berdasarkan menu yang dipilih oleh pengguna.

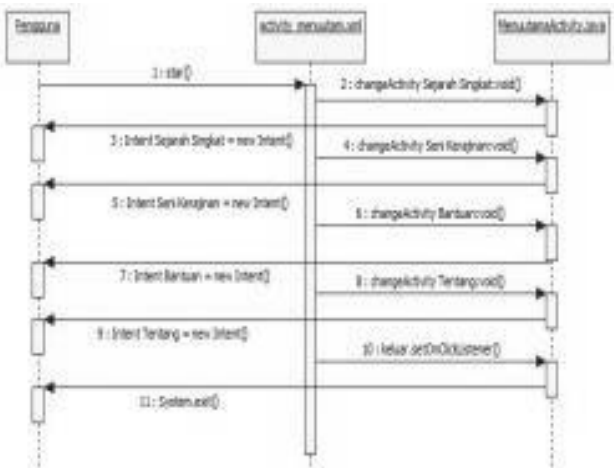

Gambar 3.Sequence DiagramMenu Utama

2) Sequence Diagram Sejarah Singkat Sequence Diagram Sejarah Singkat memperlihatkan urutan aksi yang terjadi ketika pengguna (user) memilih menu sejarah singkat kalimantan tengah lalu sistem akan menampilkan informasi sejarah singkat kalimantan tengah. 


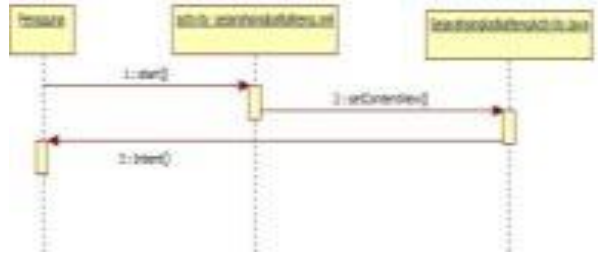

Gambar 4.Sequence Diagram Sejarah Singkat

3) Sequence Diagram Seni Kerajinan Tangan

Sequence Diagram Seni Kerajinan Tangan memperlihatkan urutan aksi yang terjadi ketika pengguna (user) memilih menu seni kerajinan tangan. Sistem akan menampilkan daftar seni kerajinan tangan ketika pengguna (user) memilih salah satu daftar sesuai dengan database, maka sistem akan menampilkan informasi seni kerajinan tangan.

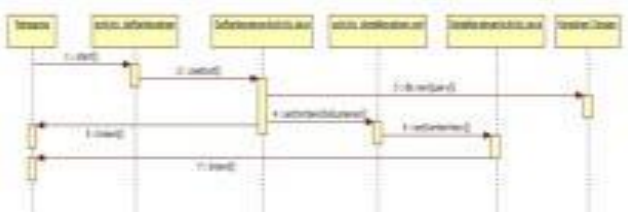

Gambar 5.Sequence Seni Kerajinan Tangan

4) Sequence Diagram Daftar Kabupaten

Sequence Diagram Daftar Kabupaten memperlihatkan urutan aksi yang terjadi ketika pengguna (user) memilih menu seni kerajinan tangan lalu sistem akan menampilkan daftar Kabupaten. Ketika salah satu daftar Kabuaten dipilih maka sistem akan menampilkan daftar seni kerajinan tangan.

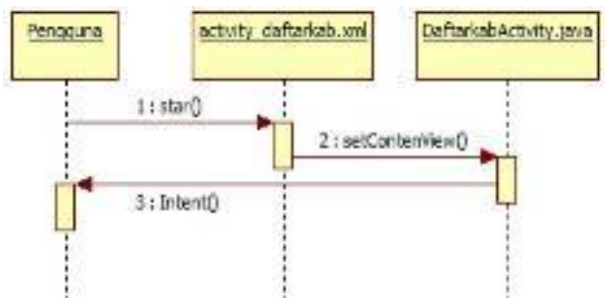

Gambar 6.Sequence Diagram Daftar Kabupaten

\section{5) Sequence Diagram Bantuan}

Sequence Diagram Diagram Bantuan memperlihatkan urutan aksi yang terjadi ketika pengguna (user) memilih menu bantuan, maka sistem akan menampilkan informasi isi bantuan.

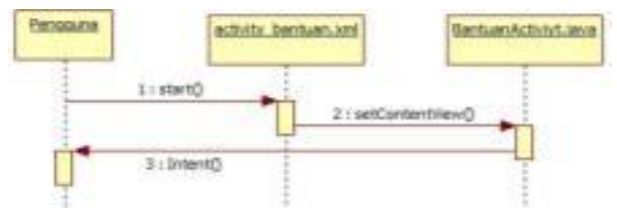

Gambar 7.Sequence Diagram Bantuan

6) Sequence Diagram Tentang

Sequence Diagram Tentang memperlihatkan urutan aksi yang terjadi ketika pengguna (user) memilih menu bantuan, maka sistem akan menampilkan informasi isi tentang.

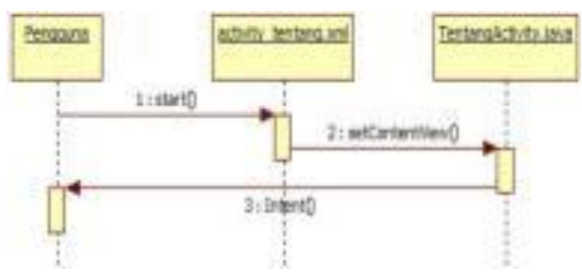

Gambar 8.Sequence Diagram Tentang 
d. Aktivity Diagram

Aktivity diagram berfungsi untuk menggambarkan aliran aktivitas yang ada dalam aplikasi yang dirancang, dimana meliputi proses awal dan proses akhir yang terjadi pada saat aplikasi sedang digunakan ketika pengguna berinteraksi dengan sistem. Pada aplikasi ini terdapat beberapa aktivitas yang terjadi sesuai dengan menu yang disajikan. Adapun aktivitas-aktivitas tersebut dapat dijabarkan sebagai berikut:

1) Activity Diagram Menu Utama

Penguna (user) memulai aktivitas dengan menajalankan aplikasi Pengenalan Seni Kerajinan Tangan, sistem menampilkan splash screen selama 3 detik lalu sistem menampilkan menu utama.

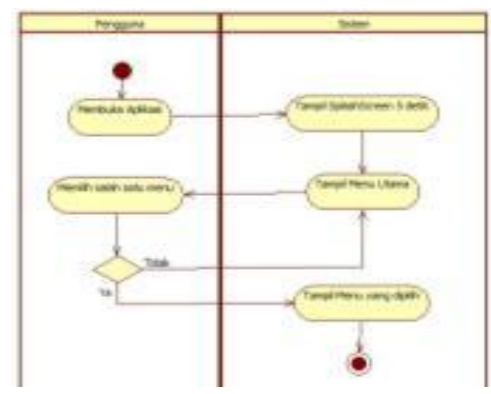

Gambar 9.Aktivity Diagram Menu Utama

2) Activity Diagram Sejarah Singkat Kalimantan Tengah

Pengguna (user) memulai aktivitas dengan memilih menu sejarah singkat Kalimantan Tengah, lalu sistem menampilkan informasi sejarah singkat Kalimantan Tengah.

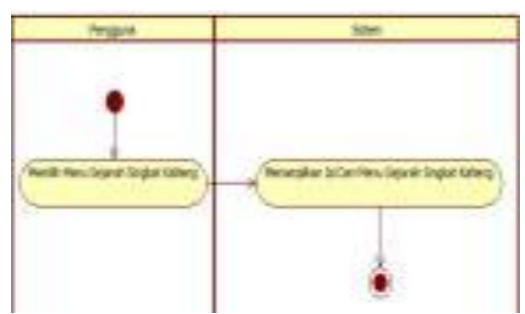

Gambar 10.Aktivity Diagram Sejarah Singkat Kalimantan Tengah

3) Activity Diagram Kerajinan Tangan

Ketika pengguna (user) memulai aktivitas dengan memilih menu seni kerajinan tangan, maka sistem akan menampilkan daftar kabupaten. Jika dipilih salah satu daftar kabupaten maka akan tampil daftar seni kerajinan tangan apabila salah satu daftar dipilih akan tampil detail seni kerajinan tangan yang berisi informasi seni kerajinan tangan.

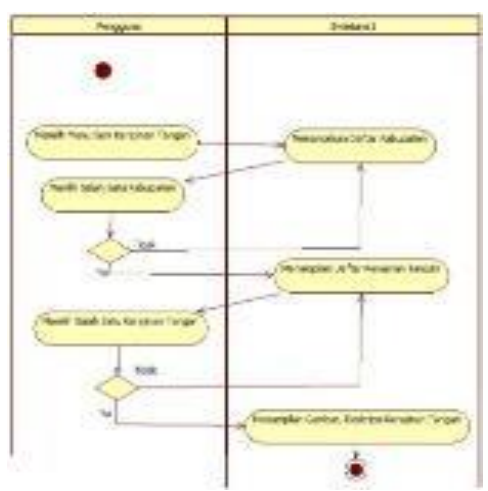

Gambar 11.Aktivity Diagram Kerajinan Tangan 
4) Activity Diagram Bantuan

Pengguna (user) memulai aktivitas dengan memilih menu bantuan lalu sistem akan menampilkan isi dari menu bantuan.

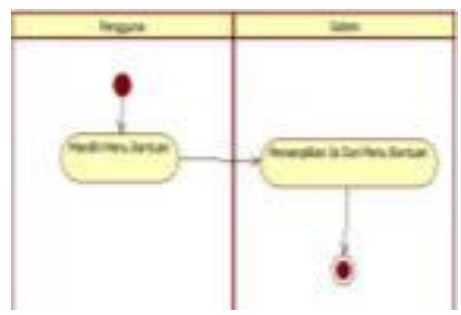

Gambar 12. Aktivity Diagram Bantuan

5) Activity Diagram Tentang

Pengguna (user) memulai aktivitas dengan memilih menu tentang lalu sistem akan menampilkan isi dari menu tentang.

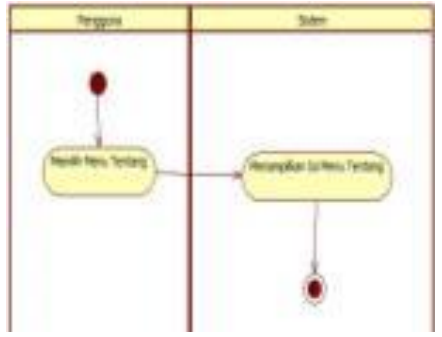

Gambar 13. Aktivity Diagram Tentang

\section{PEMBAHASAN HASIL}

Manual program merupakan konsep untuk menguraikan penggunaan program aplikasi Pengenalan Seni Kerajinan Tangan Masyarakat Dayak Propinsi Kalimantan Tengah secara keseluruhan, mulai dari cara menjalankan program untuk pertama kali, mengoperasikan tombol-tombol navigasi dan proses lainnya di dalam program. Sehingga dapat memudahkan pengguna untuk menggunakan aplikasi. Berikut uraian penggunaan program "Aplikasi Pengenalan Seni Kerajinan Tangan Masyarakat Dayak Provinsi Kalimantan Tengah berbasis Android":

\section{a. Cara Menjalankan Program}

Aplikasi pengenalan seni kerajinan tangan ini terdiri dari file setup/package berekstensi ".apk" yaitu Seni Kerajinan Tangan.apk berupa file master yang dapat di-install disetiap perangkat mobile berbasis Android. Untuk dapat menggunakan program Aplikasi Pengenalan Seni Kerajinan Tangan Masyarakat Dayak Provinsi Kalimantan Tengah ini maka perlu dilakukan instalasi program. Setelah ter-install pada perangkat mobile berbasis Android, maka akan terdapat aplikasi pada menu perangkat mobile dengan nama Seni Kerajinan Tangan yang dapat digunakan untuk menjalankan aplikasi tersebut.

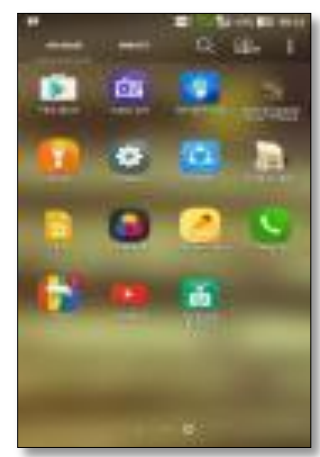

\section{Gambar 14. Aplikasi Seni Kerajinan} Tangan Pada Perangkat Mobile 
Pada saat pertama kali pengguna menjalankan aplikasi akan muncul form Splash Screen dan dialog progress proses copy database, setelah itu akan tampil form Menu Utama.

b. Menu Utama

Pada halaman ini pengguna disuguhkan tampilan menu utama dari aplikasi pengenalan seni kerajinan tangan. Di halaman menu utama, pengguna dapat memilih menu yang tersedia.

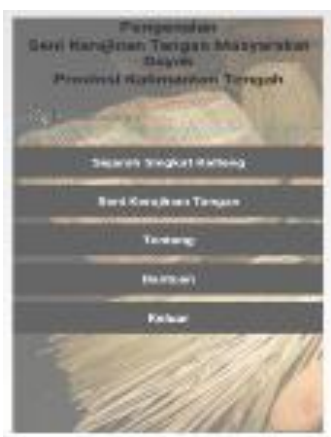

Gambar 15. Menu Utama

\section{Keterangan:}

1. Pencarian Seni Kerajinan

2. Tombol masuk ke menu "Sejarah Singkat Kalimantan Tengah"

3. Tombol masuk ke menu "Seni Kerajinan Tangan"

4. Tombol masuk ke menu "Tentang"

5. Tombol masuk ke menu "Bantuan"

6. Tombol untuk menutup atau keluar dari aplikasi "Keluar".

c. Dialog Pencarian Seni Kerajinan Tangan
Untuk menggunakan pencarian pengguna mengetik kan nama seni kerajinan tangan pada dialog pencarian maka akan tampil daftar seni kerajinan sesuai kata kunci pencarian.

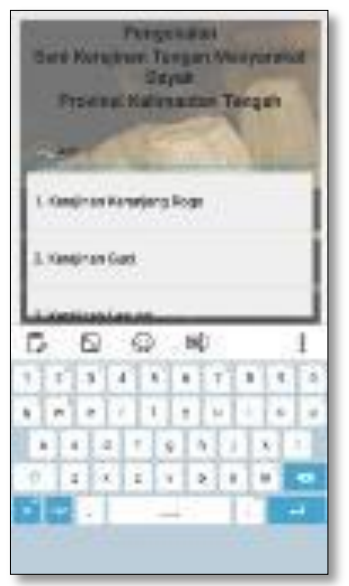

Gambar 16. Dialog Pencarian Seni Kerajinan Tangan

d. Menu Sejarah Singkat Kalimantan Tengah

Pada halaman ini pengguna akan disuguhkan tampilan yang berisi sejarah singkat kalimantan tengah berupa teks dan terdapat fitur untuk mengubah teks menjadi suara dengan menekan tombol suara.

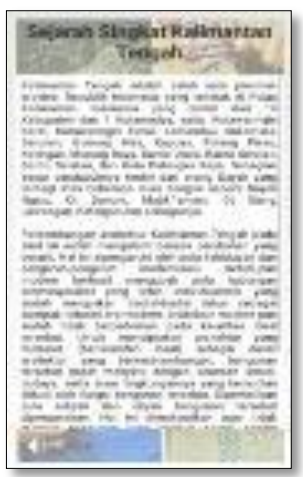

Gambar 17.Menu Sejarah Singkat KalTeng 


\section{Keterangan:}

1. Isi sejarah singkat Kalimantan Tengah

2. Tombol pengubah teks menjadi suara

3. Tombol berhenti memutar suara

e. Menu Seni Kerajinan Tangan

Ketika menu seni kerajinan tangan di tekan akan tampil halaman daftar Kabupaten.

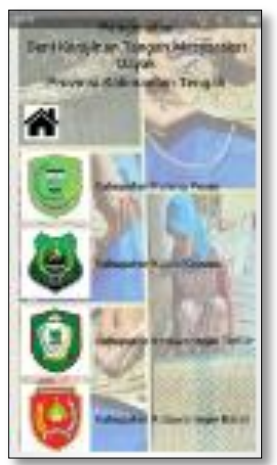

Gambar 18. Daftar Kabupaten

\section{f. Daftar Seni Kerajinan Tangan}

Jika salah satu daftar ditekan akan menampilkan halaman seni kerajinan yang berasal dari kabupaten tersebut pada halaman ini terdapat fitur pencarian.

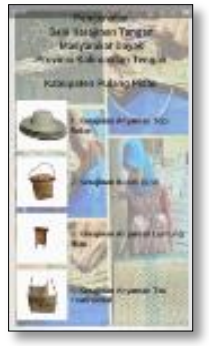

Gambar 19 . Daftar Seni Kerajinan Tangan g. Detail Seni Kerajinan Tangan

Jika salah satu daftar seni kerajinan tangan ditekan maka akan tampil detail seni kerajinan tangan berupa gambar dan penjelasan seni kerajinan tangan, pada halaman ini juga terdapat fitur merubah teks menjadi suara.

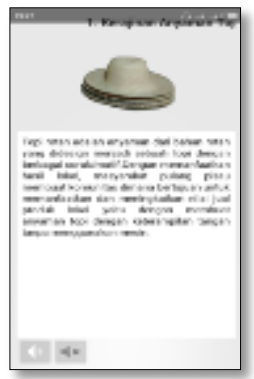

Gambar 20. Detail Seni Kerajinan Tangan

\section{Keterangan:}

1. Gambar seni kerajinan tangan

2. Penjelasan seni kerajinan tangan berupa teks

3. Tombol merubah teks menjadi suara

4. Tombol stop pemutar suara

h. Menu Bantuan

Jika menu bantuan ditekan maka akan tampil halaman Bantuan yang berisi cara penggunaan aplikasi.

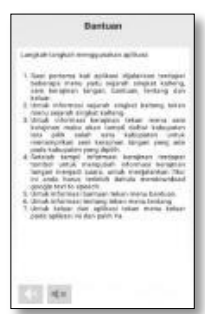

Gambar 21. Menu Bantuan 
i. Keluar

Ketika pengguna menekan tombol menu "Keluar" lalu memilih "Ya" pada saat dialog konfirmasi ditampilkan, maka pengguna akan mengakhiri/keluar dari aplikasi. jika memilih "Tidak" maka pengguna akan kembali pada tampilan menu utama aplikasi.

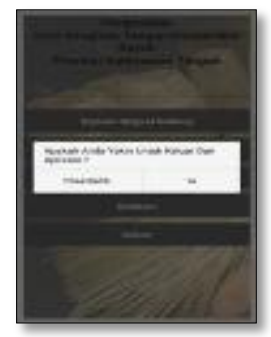

Gambar 43. Keluar Dari Aplikasi

\section{KESIMPULAN}

Berdasarkan hasil penelitian, dapat diambil kesimpulan terhadap pembuatan Aplikasi Pengenalan Seni Kerajinan Tangan Masyarakat Dayak Provinsi Kalimantan Tengah Berbasis Android yaitu sebagai berikut:

1. Aplikasi dapat dibangun dengan menggunakan bahasa pemrograman Java yaitu Eclipse.

2. Menggunakan UML (Unified Modelling Language) sebagai basis data untuk pembuatan aplikasi.

3. Menghasilkan sebuah aplikasi smartphone yang tidak memerlukan koneksi internet (offline), yaitu aplikasi Pengenalan Seni Kerajinan Tangan Masyarakat Dayak Provinsi Kalimantan Tengah yang dapat digunakan oleh siapapun.

4. Aplikasi Pengenalan Seni Kerajinan Tangan ini menampilkan Gambar, membaca teks dengan teks to speech dan diiringi dengan instrumen pada saat membuka aplikasi.

5. Aplikasi Pengenalan Seni Kerajinan Tangan dapat diinstal pada Operating System berbasis Androiddengan OS minimal Android 4.1 (Jelly Bean).

\section{DAFTAR PUSTAKA}

Aditya, N. A., 2011. Jago PHP \& MySQL, Dunia Komputer Bekasi.

Irsyad, H., 2015. Aplikasi Android Dalam 5 Menit. Jakarta. Kompas Gramedia.

Nugroho, A. 2009. Rekayasa Perangkat Lunak Menggunakan UML dan Java. Yogyakarta, Andi.

Nugroho, AT. 2013. Step By Step Menjadi Programmer Android. Yogyakarta, Andi.

Nugroho, AT., 2013. Android Programming with Eclipse. Yogyakarta, Andi.

Sugianto, M., 2011. Seri Belajar Cepat Adobe Photoshop CS5. Yogyakarta, Andi. 